\title{
MASTERING COMPLEXITY IN TAKT PLANNING AND TAKT CONTROL - USING THE THREE LEVEL MODEL TO INCREASE EFFICIENCY AND PERFORMANCE IN CONSTRUCTION PROJECTS
}

\author{
Janosch Dlouhy $^{1}$, Marco Binninger ${ }^{2}$, Svenja Oprach ${ }^{3}$ and Shervin Haghsheno ${ }^{4}$
}

\begin{abstract}
When scheduling a construction project, resource consumption, efficiency of the trades, external influences and the possible changes within the construction process must be taken into account. Hence, the complexity of the construction schedule and an exact planning is difficult. So often the time buffers are balancing the unexpected events. That's the reason the full potentials of the construction project are often missed. The approach of Takt Planning and Takt Control (TPTC) offers a possibility to dimension buffers and schedule them transparently. This approach is often seen as a rigid and complicated procedure. The planning has to be adapted with a huge effort to changes in the construction process and therefore often does not show the real image of the construction site. The three-level model tries to structure the method for all participants. This paper aims to improve the simplicity of dimensioning value, time and activities in Takt Planning. Performance indicators can provide information about the dimensioning and its adaptation to the construction process. Thus, TPTC can be seen as a flexible method for controlling the complexity of construction planning and excellerate efficiency of the hole project.
\end{abstract}

\section{KEYWORDS}

Lean construction, Takt, three-level model, complexity

\footnotetext{
1 Research Fellow, Karlsruhe Institute of Technology, Germany, +49-721-608-42168, janosch.dlouhy@kit.edu

2 Research Fellow, Karlsruhe Institute of Technology, Germany, +49-721-608-44124, marco.binninger@kit.edu

3 Research Fellow, Karlsruhe Institute of Technology, Germany, +49-721-60844124,svenja.oprach@kit.edu

4 Professor, Karlsruhe Institute of Technology, Germany, +49-721-608-42646,
} shervin.haghsheno@kit.edu 


\section{INTRODUCTION}

In many construction projects, Takt Planning in a classic application, is often seen as a complicated and rigid scheduling process. Conventional the Takt of the individual trades is based on mass determination of a construction project. By the use of the Line of Balance (LOB) the different paces become evident, as shown in the figure 1 Subsequently a harmonization of pace is done with a complex buffer dimensioning (cf. Moura et al., 2014).

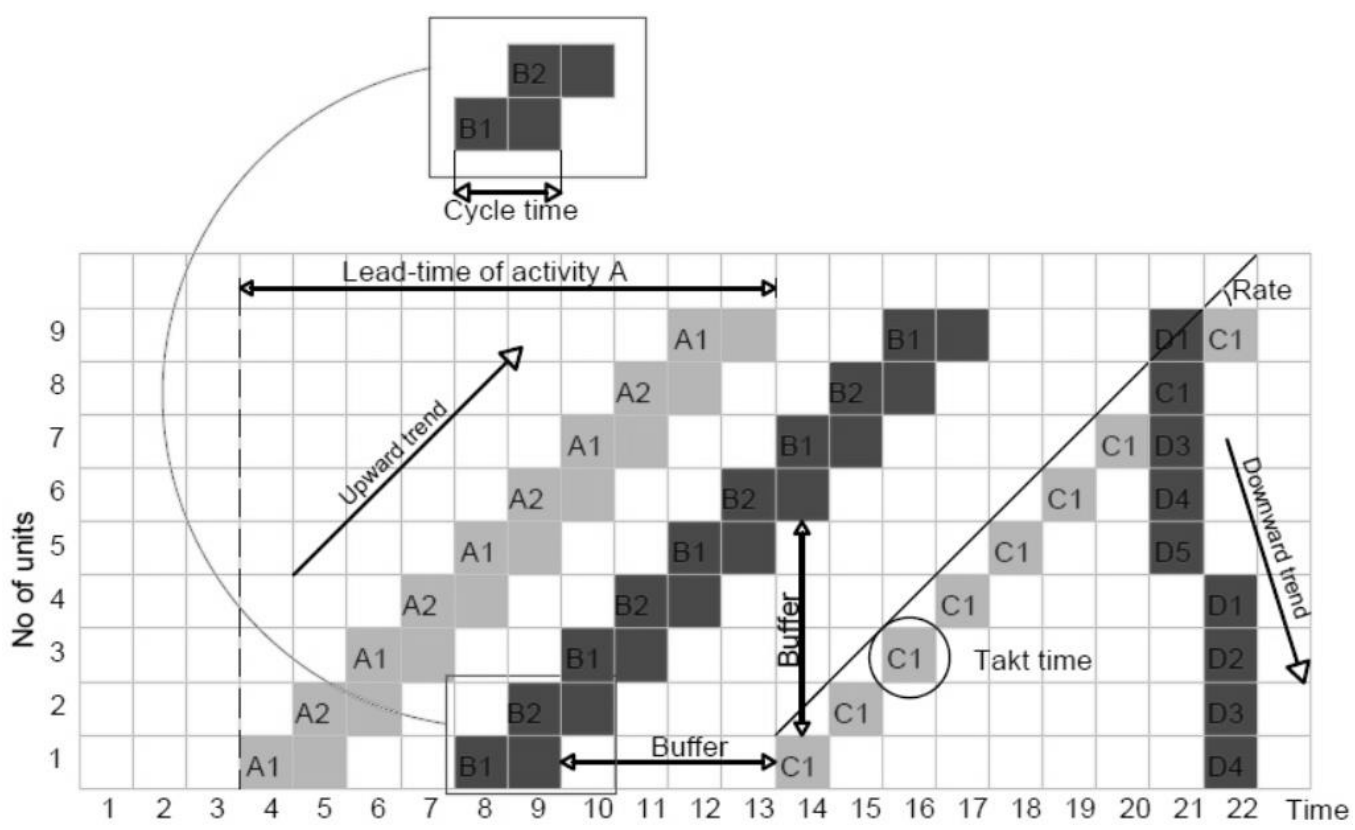

Figure 1: Buffer Dimensioning (Moura et al., 2014, p. 712)

A quick and transparent reaction in order to change the schedule is prevented due to the detailed planning and post calculation. Therefore, a standardization of the product and an always similar process with as little disruptive factors, is often the main condition for Takt. In doing so, rigid requirements are given to the contributors of the construction project, in order to comply with the Takt Plan. These requirements create little acceptance with the contributors and already with minimum disruption in the procedure, for example caused by lacking material, disease or default in the rendering of services, the takt plan fail to comply with the reality on the construction site. Therewith, a high lack of precision during the implementation of the project is created, because the target-actual comparison can no longer be methodical identified.

Takting, as a principle, is applied since many years (cf. Nezval, 1960)(cf. Horman et al., 2003), but not transmitted and used up as an extensive construction method. In order to represent a realistic image of the construction site in the Takt Plan, a systematology of generalities for the simplification of the scheduling and the possibility to react to modifications during the construction workflow is needed. In this paper generalities are introduced, which should reduce the complexity of takting. 


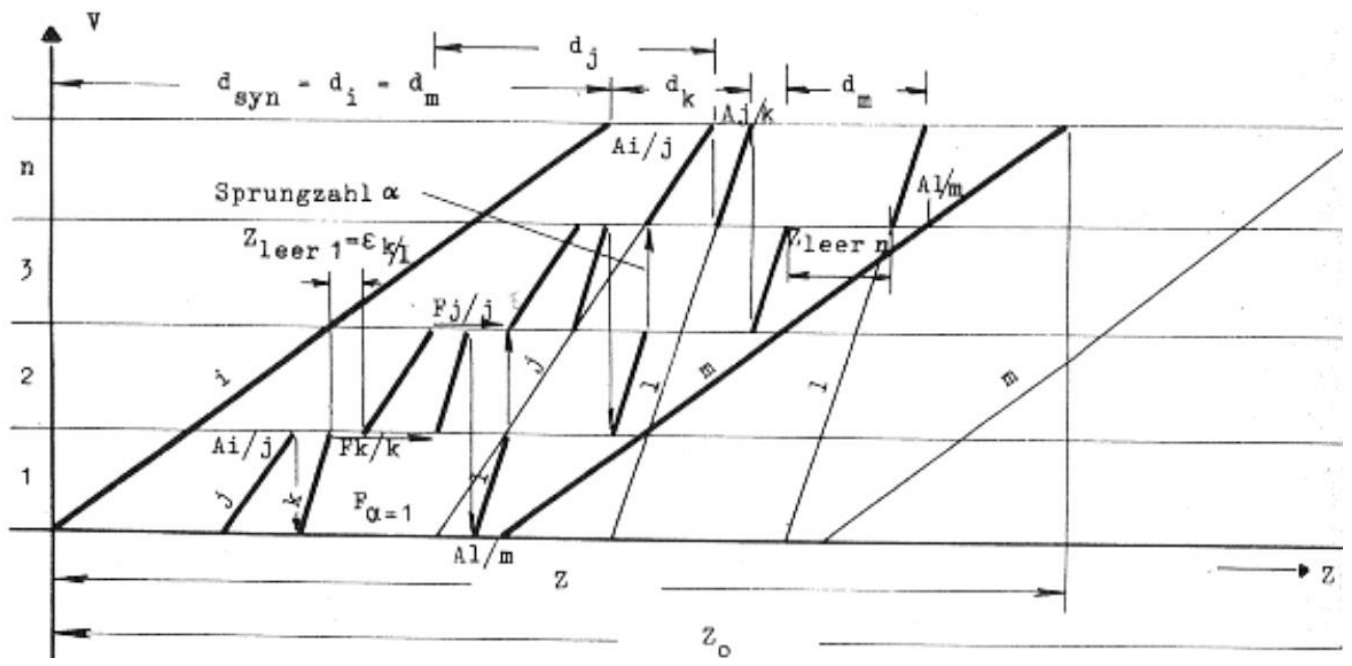

Figure 1: Example of Takt optimization by mathematical angles(Schub, 1970, p. 45)

\section{THEORETICAL FOUNDATIONS}

The term „Takt" derives from the Latin word „tactus“, which means „touch, feeling or Beat" (Dudenredaktion, 2014). In the 16th century Takt was defined as ,a rhythm triggered by a touch.“ (Dudenredaktion, 2014)(Haghsheno et al., 2016, p. 53). Therefore, a Takt can be understood as an initiator, which causes an action in regular intervals.

Takt is not an one-dimensional unit, but it is an interaction of different dimensions. By considering the components of Takt principles in figure 2, the following three dimensions of Takt become visible:

1. Takt time is the time dimension. For every Takt in a system is it the same or scalable. It creates a generally valid rhythm.

2. Takt process or Takt content represent the ongoing, which takes place in the Takt. This dimension is often combined with Takt time. (cf. Verband für Arbeitsstudien, 1985, p. 282).

3. Takt location describes the place, where the Takt process happens. It is not necessarily a physical place. 


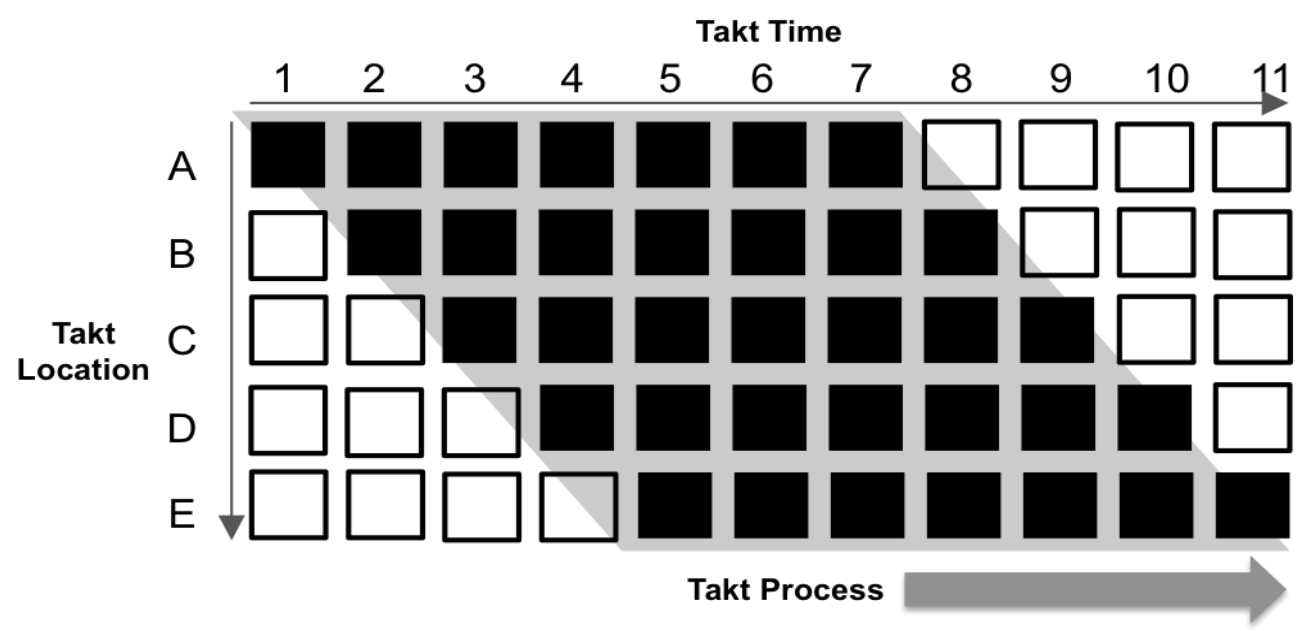

Figure 2: Example of a simple Takt schedule

Takt Planning can be defined as: in construction work is moving through the product, the takt (if there is to be a takt) has to be established by the plan. This is done by dividing the object (e. g. the building or road) into zones and deciding a construction direction in which work is to move"(Bølviken et al., 2015, p. 95)The trades are moving in the construction direction through the zones in a constant speed, the Takt Time.

Whereas the Takt Control relates to the control and adaptation of the Takt Plan during the construction. „Takt Control is responsible for maintaining the necessary stability. Systematic and short-cycled construction control is a significant success factor in the process of construction projects.." (Haghsheno et al., 2016, p. 8) The planed process is approached more and more to an realistic image of the construction site. Disorders get eliminated and the process gets more stable. Accordingly, the principle of Takt has the task of standardizing and systematization of the procedures, in a way that the process is stable without any further reorganization or modification. The first step thereby is not the optimization of the system, but it is the stabilization. Based on a stable and foreseeable procedure the optimization is supported.

Due to the differentiation of the Takt into three dimensions, the complexity of an optimization becomes more difficult. Currently, for simplicity, often at least one of the dimensions; time, location or process, is held. If it is possible to influence, in a flexible way, the interaction between the three dimensions in a simple system and to analyze their effects, the Takt Planning could be essentially simplified.

\section{TECHNICAL TAKT PLANNING AND TAKT CONTROL IN CONSTRUCTION by the Karlsruher Institute of Technology (2015)}

The approach, developed at the Karlsruher Institute of Technology, represents a further development of parts of Kiser's approach. The basics has been published at the IGLC Conference 2016 (cf. Haghsheno et al., 2016). The method of Technical Takt Planning and Takt Control was described in-depth and defined in the following year at the IGLC Conference 2017 (cf. Binninger et al., 2017a). The method is furthermore specified in 
additional publications (cf. Binninger et al., 2017b); (cf. Binninger et al., 2016). The ambition is it to illustrate existing practical implementations in a methodical approach in Germany and to continue the developments systematically. In the publication of Binninger et al.(2017a) the following 12 steps of the Takt schedule are described.

1) Define functional areas (2) Define priorities 3) Pick one functional area 4) Define SSU(s) for one functional area 5) Define work packages for every SSU (standard space unit - the smallest area you can work with the defined work packages) 6) Do the calculation oft he amount of work for every step 7) Allocate detailed work steps to work packages 8) Determine Takt time and Takt area 9) Takt levelling 10) Combine the work packages best for determined Takt time and Takt area 11) Do steps 3 to 6 for all functional areas 12) Prepare the takt schedule and determine milestones in order to costumer priority.

Regarding the work content there are different detail levels to be distinguished: On the working level there are work steps, in the Takt plan work packages are defined and on a customer view there are phases. To master the complexity of the work content in step 7 and step 10, there is a double assignment, which is defined as double packaging and double sequencing.

The double packaging and double sequencing represents at the current status of research the first type of such a solution. The multiple packaging allows an itemization of the work steps whilst simultaneous overlapping level of detail. As shown in figure 3, the smallest work steps are single-origin allocated at first to the trades, whereby useful work packages are created. In step 2 those work packages are combined in a necessarily order, where a process sequence is build. Thereby sequenced work packages (trade sequence) are created out of the work steps.

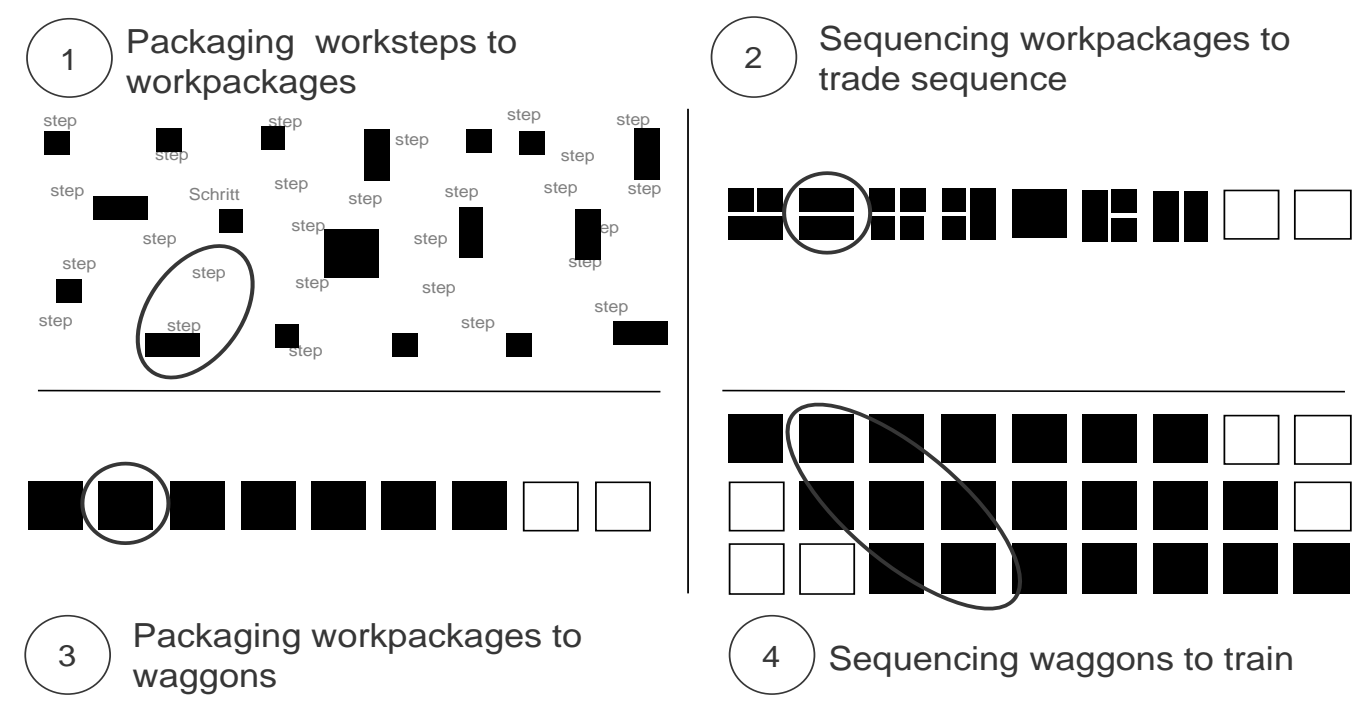

Figure 3: Double packaging and double sequencing 
In this approach Takt Control is described independently. The collection of datasets and indicators (Binninger et al., 2017a, p. 6), as well as the adaptation of processes during the construction, are described in Takt Planning and Takt Control (cf. Binninger et al., 2017b). The integration of the customers regarding the construction direction with the defined milestones has been considered in the foundations and also in the twelve steps of implementation.

On the basis of the introduced technical Takt Planning and Takt Control approach, the methodic proceeding for a simple use of the three Takt dimensions; Takt time, Takt process and Takt location, is presented.

\section{METHODICAL APPROACH}

Takt Planning and Takt Control is divided into different levels of itemization with the objective of a reduction of complexity and for a differentiation of common rules (Dlouhy et al., 2016). These levels serve as well for a targeted and structured communication.

\section{MACRO LEVEL}

The macro level of the three-level method serves as communication and decision basis for the customer. It contains information with reduced depth of detail, which is needed for strategic decisions referred to the total building process. The information of the lower levels is bundled and coordinated on a project combining working method. The level is used to optimize the construction phases among each other and with the leading and successive stages. The complete but simplified representation of the construction project gives the possibility to the builder (construction client) to have a decisive and transparent overview. The takted areas of the construction project are described as a train of work with wagons. The wagon defines a kind of shell of a Takt area in a given Takt time, which defines the Takt. In this way, a working Takt is described by a wagon. The priority of the area is determined, from the perspective of the client, on the macro level. Takt time and Takt area are defined in the macro takt plan and if necessary adjusted in the norm level after their planning.

- Time: Milestones define the priority of the client

- Process: functional areas define the number of different process sequences, from which a minimum of trains of work is derived. Within a train of work, the process is represented in wagons (see figure 3 - step 3 and 4 ).

- Location: functional areas define areas, which contains different performance steps.

In figure 4 a Taktplan on the macro level is shown with a weekly Takt time, ten Takt areas as well as one train of work. For an simple communication with the client the phases as structure (yellow), cladding (green) and finished (blue) are marked in colours without representing the detailed work content (Oprach et al., 2017). 


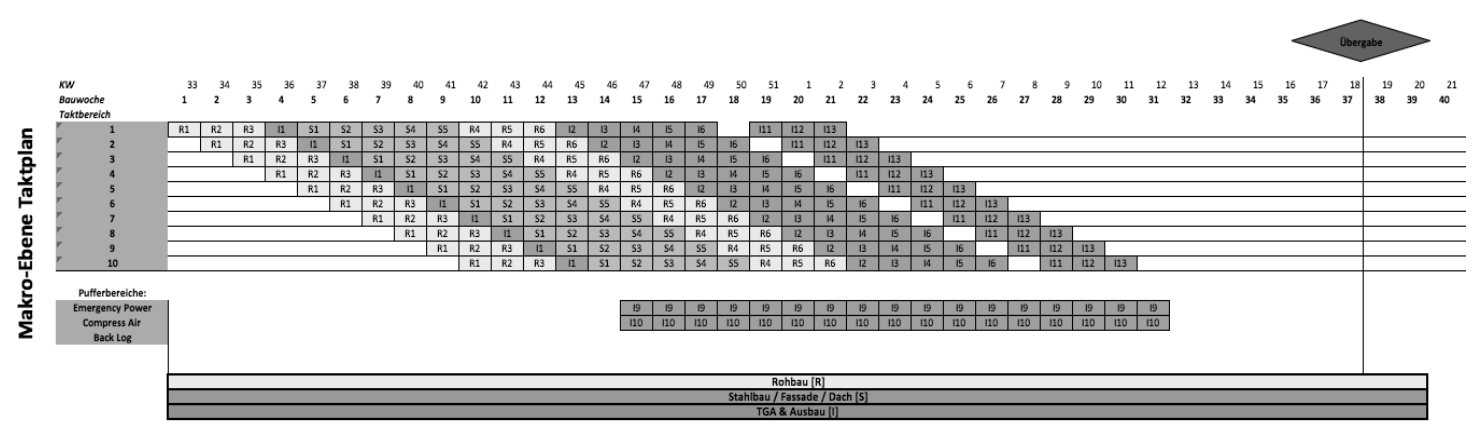

Figure 4: Taktplan on Macro level (Oprach et al., 2017)

\section{NORM LEVEL}

The norm level of the three-level method illustrates the processes of the construction coordination with a middle degree of detail (see figure 5). Information and requirements, out of the macro level, become attuned to the project and the construction progresses are planned and coordinated. Single processes and their interfaces were optimized, what allows a stable flow on the progress. They describe the Takt Planning on basis of a temporal and spatial preliminary decision based on the macro level. In the norm level, the wagons of the macro level are detailed by working packages per trade. For every working package of the process sequence, all the working steps are identified for the micro level. By changes of manpower, combinations of Takt areas, or by type and number of the used tools and machines, the single work packages can be harmonized. The result is a work sequence of trades consisting out of work packages with defined capacity and investments. The work package gives statements on required materials and machines, as well as on other capacities linked to the Takt. Non-replicable work packages, are not part of the Takt and are defined as Workable Backlog. Those could be preferred, used as work compensation parallel to Takt Planning or put after.

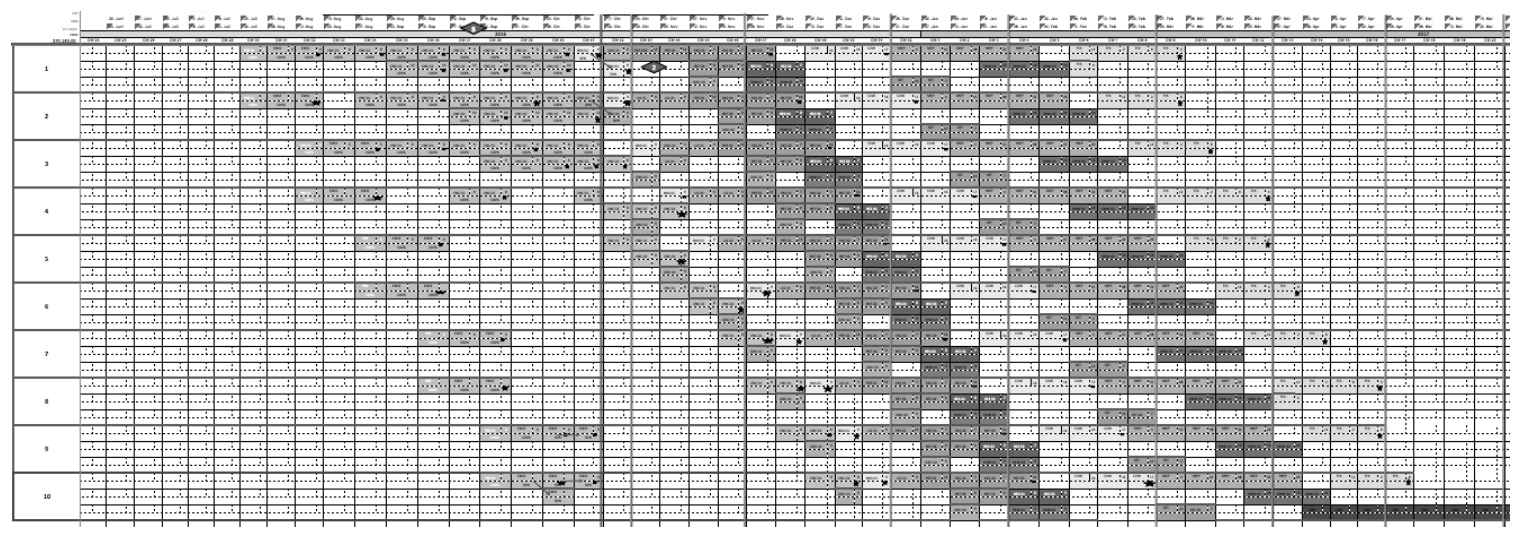

Figure 5: Taktplan on Norm level (Oprach et al., 2017)

- Time: Takt time

- Process: Work packages (figure 3-step 2)

- Location: Takt area 


\section{MICRO LEVEL}

The micro level is the lowest and at the same time the most detailed level of the threelevel method. It represents the actual proceeding processes of the value adding level and controls the short-cycled implemented work (see figure 6). Instructions are given from the norm level and the micro level gives back data and information to the upper levels. Thereby, the itemization of the work packages out of the norm level on work steps as well as the Takt Control of the construction project takes place. The Takt Control is led by short-cycled meetings. Comparable to the meetings of the shopfloor management of the stationary industry, the information out of the Takt status meetings are recorded on a takt control board for visualization, documentation. If necessary they are converted into indicators (Binninger et al., 2016a, p.7f.). Shopfloor could be translated as place where value is added or workspace. Shopfloor-Management describes the leading and steering of these place where value is added(cf. Peters, 2009, p. 217).

- Time: amount of work of the work steps

- Process: Work Steps (figure 3-step 1)

- Location: SSU

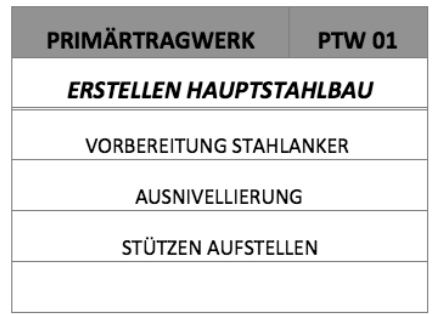

Figure 6: Work package on Micro level (Oprach et al., 2017)

In sum it can be said, that the micro level the data input of single trades in the planning serves. In the norm level the harmonization takes place. The macro level is used for the simplified representation and communication of the construction progress, from the perspective of the customer. The differentiation of the three levels in Takt Planning guides the planner from a variety highly detailed data and information to a holistic and simplified description (see figure 7). The same differentiation of the three levels within Takt Control gives the possibility to identify the cause-source and their effects in a fast way, caused by deviations. Here in the micro level root causes are documented, with the upper two levels the effects on time, area and process change can be easily detected by scaling up. Due to appropriate indicators, deviation from the plan can be quickly and efficiently highly aggregated up to milestones. The Takt control based on the three levels is done and proved by the authors in several projects. 


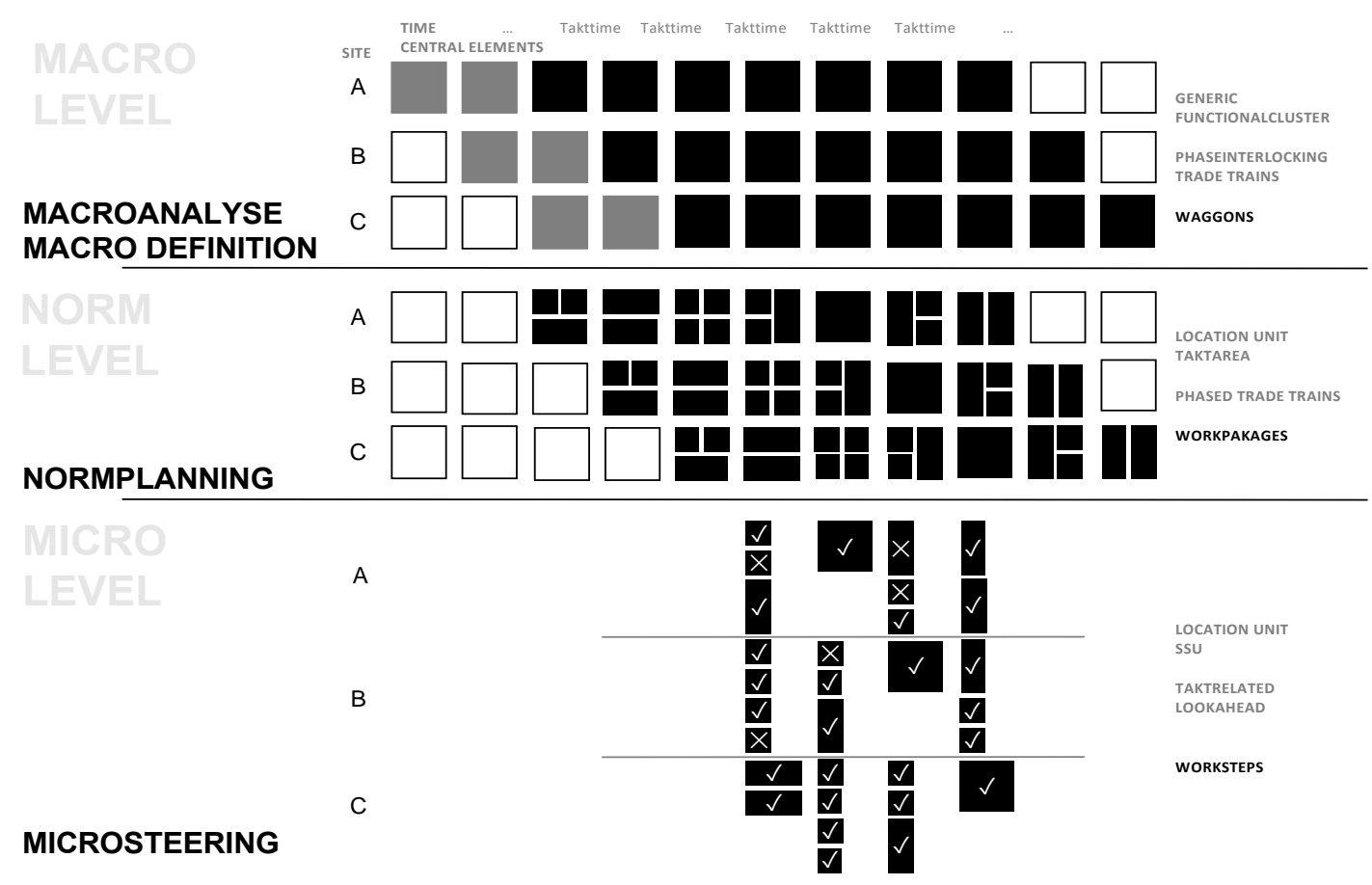

Figure 7: The three-level model

\section{INDICATOR AT THE THREE LEVEL}

Micro level: The PPC_Micro (percentage planned completed) on micro level specifies the compliance of the planed working steps. Furthermore, reasons of neglects on working steps can be shown (e.g. lack of manpower, or preliminary work).

Norm level: The PPC_Norm on norm level specifies the compliance of the planed working packages. The performance progress of the entire project, the single areas or the single trades can be evaluated by this.

Marco level: As on the micro and norm level, the compliance of the milestones can be measured and a project related buffer management can be executed. The transparence in the project enables the representation of superior indicators on the total flow, stability, efficiency and on the value of the total project.

\section{DISCUSSION AND CONCLUSION}

Takt planning and Takt Control is seen in a lot of projects as a very complex and rigid procedure: The trades are individually optimized and, in each case, harmonized with the construction site flow by a complex buffer dimensioning. In case of changes of the plan, the updating of the Takt plan causes a lot of working steps. Due to this effect trades as forced to adhere to a rigid Takting. In another case the Takt plan doesn't represent the real image of the construction due to variations. The complexity of Takting is mostly caused by mastering of the three dimensions. These are Takt time, Takt process an Takt location. To be able of simplifying and mastering all of the three dimensions, different abstraction and communication levels are needed. With the help of the Three-Level 
Method and by the double packaging and sequencing a possible solution can be created as shown in this paper. The dimensioning on the three levels is accommodated in different abstraction levels. Thereby every level can be taken individually, but a change within one level causes mechanisms in the other levels. Indicators at all three levels provide guidance on a disturbance of the construction workflow and imply measures to update the Takt plan.

\section{REFERENCES}

Binninger, M., Dlouhy, J., Haghsheno, S., 2017a. Technical Takt Planning and Takt Control in Construction., in: 25th Annual Conference of the International Group for Lean Construction., pp. 605-612.

Binninger, M., Dlouhy, J., Oprach, S., Haghsheno, S., 2016. Methods for Production Leveling - Transfer from Lean Production to Lean Construction, in: 24th Annual Conference of the International Group for Lean Construction..

Binninger, M., Dlouhy, J., Steuer, D., Haghsheno, S., 2017b. Adjustment Mechanisms for Demandoriented Optimisation in Takt Planning and Takt Control, in: 25th Annual Conference of the International Group for Lean Construction, pp. 613-620.

Bølviken, T., Aslesen, S., Koskela, L., 2015. What Is a Good Plan? Presented at the 23rd Annual Conference of the International Group for Lean Construction, pp. 93-102.

Dudenredaktion, 2014. Duden - Die deutsche Rechtschreibung: Das umfassende Standardwerk auf der Grundlage der aktuellen amtlichen Regeln, 26. Auflage. ed. Bibliographisches Institut, Mannheim.

Haghsheno, S., Binninger, M., Dlouhy, J., Sterlike, S., 2016. History and Theoretical Foundations of Takt Planning and Takt Control, in: 24th Annual Conference of the International Group for Lean Construction.

Horman, M.J., Messner, J.I., Riley, D.R., Pulaski, M.H., 2003. Using Buffers to Manage Production: A Case Study of the Pentagon Renovation Project, in: Proceedings of the 11th Annual Conference of the Internation Group for Lean Construction (IGLC-11), Blacksburg, Virginia.

Moura, R. de S.L.M., Monteiro, J.M.F., Heineck, L.F.M., 2014. Line of Balance - Is It a Synthesis of Lean Production Principles as Applied to Site Programming of Works?, in: Proceedings of the 22nd Annual Conference of the International Group for Lean Construction., pp. 703-714.

Nezval, J., 1960. Foundations of Flowproduction in Construction, 1. Auflage. ed. Verlag für Bauwesen Berlin.

Oprach, S., Steuer, D., Dlouhy, J., 2017. Choosing the right visualization for Construction processes, 1. Auflage. Lean Construction - The Management Book: Agile Methoden and Lean Management inConstruction. Springer Gabler, Berlin.

Peters, R., 2009. Shopfloor Management: Managming the Location of Valueadding work. LOG_X, Stuttgart.

Schub, A., 1970. Problems of Taktplanning in Construction, Journal of the Bayrischen Bauindustrieverbandes. Bauverlag GmbH, Wiesbaden und Berlin. 